\title{
Case report. Ongebruikelijke presentatie van een Leydig-celtumormetastase tijdens de behandeling van een prostaatcarcinoom
}

\author{
Laura Stokkel • Henk G. van der Poel' • Sigrun I. Langbein ${ }^{2}$. J. Martijn Kerst ${ }^{3}$ Bas W. G. van Rhijn ${ }^{1}$ \\ Published online: 18 May 2018 \\ (c) The Author(s) 2018
}

\section{Samenvatting}

In dit artikel beschrijven wij een patiënt met een testosteron producerende metastase, die werd ontdekt tijdens de follow-up van een prostaatcarcinoom. De patiënt in deze casus had in zijn voorgeschiedenis een Leydig-celtumor, waarvoor hij een radicale orchidectomie rechts had ondergaan. Kort daarop werd hij gediagnosticeerd met prostaatcarcinoom. Behandeling bestond uit radicale prostatectomie en bekkenklierdissectie. Voor het recidief prostaatcarcinoom werd hij aanvullend behandeld met radiotherapie op prostaatfossa en bekkenklierstations in combinatie met drie jaar hormonale behandeling. Het testosterongehalte gedurende de hormonale therapie steeg fors. Bij verder onderzoek en chirurgisch ingrijpen bleek er sprake van een testosteron producerende Leydig-celtumormetastase in het retroperitoneum.

Trefwoorden testistumor $\cdot$ Leydig-celtumor $\cdot$ metastase $\cdot$ testosteron

\section{Case report. Testosterone producing Leydig cell tumor metastasis during the follow-up of prostate cancer, an unusual presentation}

\begin{abstract}
In this case report, we describe a patient with testosterone producing metastasis discovered during the follow-up of prostate cancer. The patient had a history of a Leydig cell tumor in the right testicle for which he had undergone a radical orchidectomy of the right testicle. Shortly after the orchidectomy, he was diagnosed with prostate cancer. The patient was treated with radical prostatectomy and pelvic lymph-node dissection. Due to recurrent prostate cancer, he received radiation to the prostatic fossa and pelvic lymph-nodes with hormonal treatment for 3 years. Under hormonal treatment, a significant increase in the testosterone level occurred. Further diagnostic evaluations and surgery revealed testosterone producing Leydig cell tumor metastasis in the retroperitoneum.
\end{abstract}

Keywords testicular tumor $\cdot$ Leydig cell tumor $\cdot$ metastasis $\cdot$ testosterone

\section{Introductie}

Laura Stokkel

1.stokkel@nki.nl

1 afdeling Urologie, Antoni van Leeuwenhoek, Amsterdam, Nederland

2 afdeling Urologie, Zaans Medisch Centrum, Zaandam, Nederland

3 afdeling Medische Oncologie, Antoni van Leeuwenhoek, Amsterdam, Nederland
Leydig-cellen, welke gelegen zijn in de peritubulaire ruimten van de testes, produceren testosteron onder invloed van luteïniserend hormoon (LH). Leydig-celtumoren (LCT's) scheiden in de meeste gevallen ook testosteron uit [1]. Ongeveer de helft van de patiënten met LCT heeft een verhoogde testosteron- of oestrogeenspiegel. De meeste LCT's zijn benigne en in $10 \%$ van de gevallen is er sprake van maligniteit [2]. In pathologisch opzicht is het moeilijk om hiertussen onderscheid te maken en in de literatuur valt te lezen dat metastasering wellicht het enige juiste criterium 


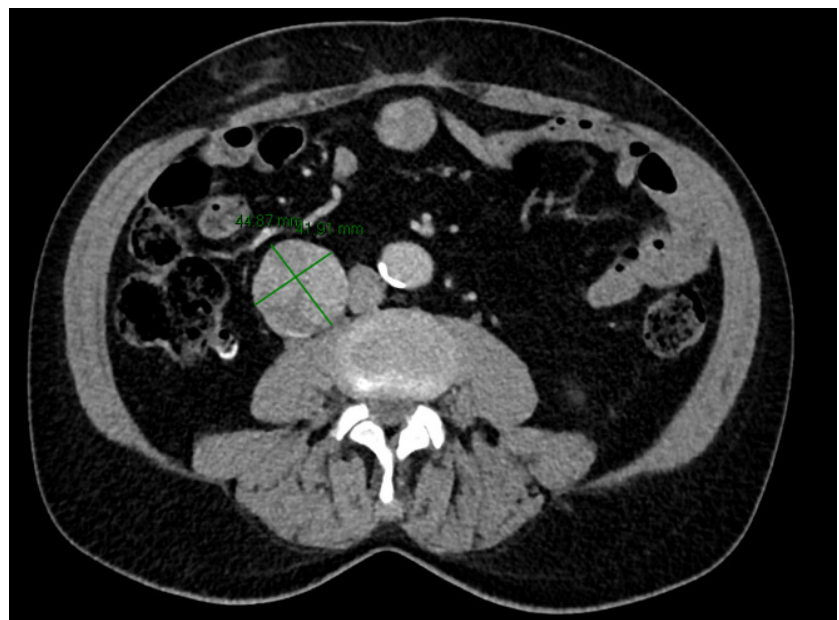

Figuur 1 CT-abdomen: een transversale doorsnede die een paracavale massa laat zien van $4,1 \times 4,3 \mathrm{~cm}$, met vrij felle aankleuring en calcificaties in de wand

is voor het vaststellen van maligne LCT [1]. Testiculaire maligniteiten zijn relatief zeldzaam. Ze zijn verantwoordelijk voor $1-1,5 \%$ van alle mannelijke maligniteiten en voor slechts $5 \%$ van alle urologische tumoren. Bijna $95 \%$ van de primaire testiculaire tumoren zijn kiemceltumoren. LCT's behoren tot de stromale tumoren en omvatten slechts 1-3\% van de testiculaire tumoren. Ze hebben een piekincidentie bij jongens van 5-10 jaar en bij mannen van 30-85 jaar. LCT's metastaseren in de regel niet en $98,5 \%$ van de patiënten presenteert zich met stadium-1-ziekte [2]. Maligne LCT's komen met name voor op hogere leeftijd. De voorkeurslocaties voor metastasering zijn retroperitoneale lymfeklieren $(70 \%)$, lever (45\%), long $(40 \%)$ en bot $(25 \%)$. Metastasen openbaren zich meestal binnen twee jaar na de diagnose [2,3]. Over het algemeen hebben LCT's die metastaseren een grotere primaire tumoromvang (mediaan 7,5 cm) dan benigne LCT's (mediaan $4 \mathrm{~cm}$ ) en ze hebben een hogere mitotische activiteit. Overleving na metastatische ziekte varieert sterk en ligt tussen 1 maand en 9 jaar, afhankelijk van de mate van metastasering [3].

\section{Casus}

Op de polikliniek werd een 65 -jarige man gezien tijdens de follow-up na behandeling van een lokaal uitgebreid prostaatcarcinoom. Het laboratoriumonderzoek toonde oplopende testosteronwaarden ondanks hormonale therapie.

In zijn voorgeschiedenis heeft hij een LCT van zijn rechtertestis waarvoor hij in 2013 een orchidectomie rechts heeft ondergaan. De tumor was $2,5 \mathrm{~cm}$ in omvang en werd radicaal verwijderd. Bij pathologisch onderzoek bracht de LCT melan-A, calretinine en inhibine tot expressie. Serumtumormarkers voor alfafoetoproteïne (AFP), beta-HCG en LDH waren niet verhoogd. Dit past goed bij een puur LCT. Negen maanden later werd hij geanalyseerd in verband met een verhoogd PSA-gehalte in het kader van een positieve

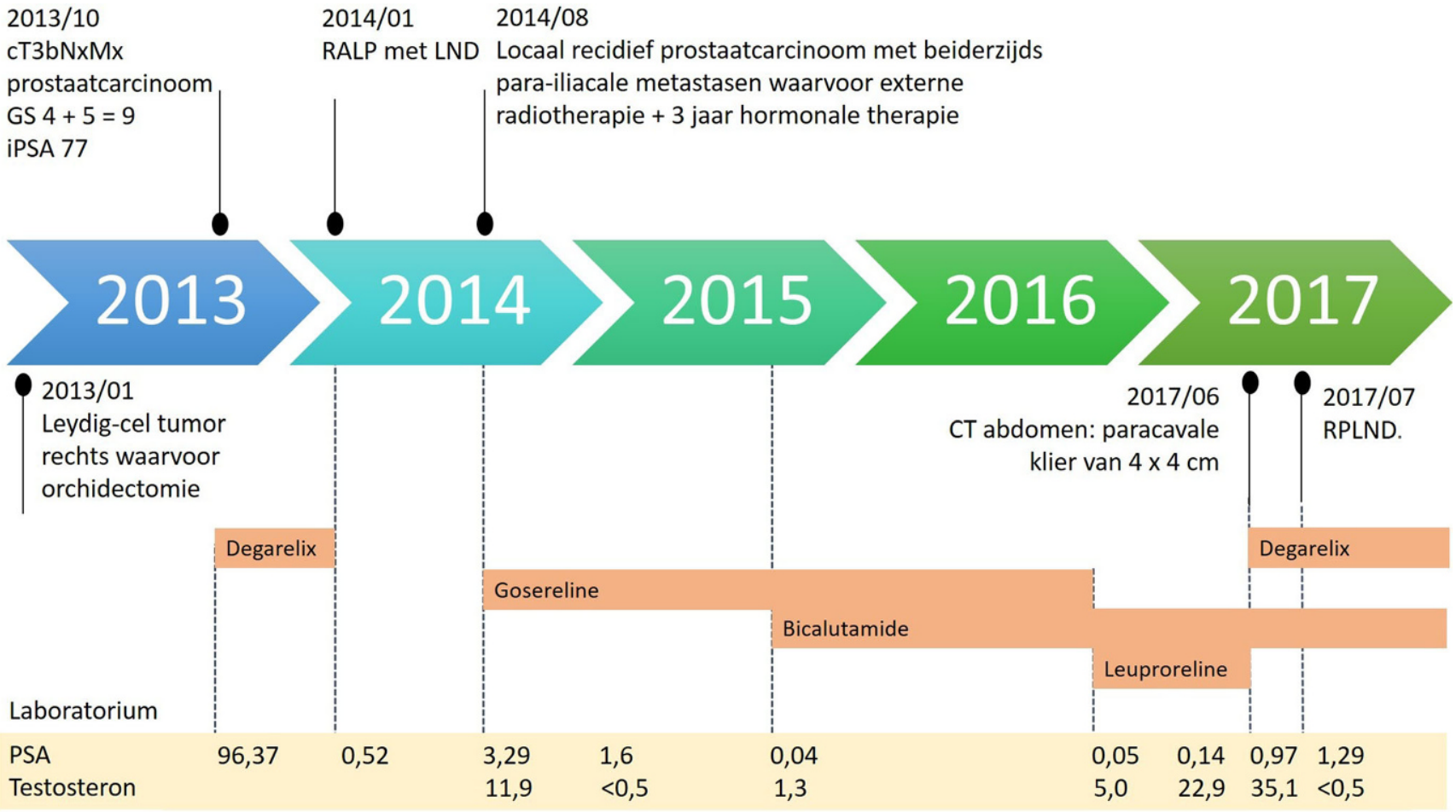

Figuur 2 Ziektebeloop van de patiënt met bijbehorende laboratoriumwaarden 
Figuur 3 a PSA-curve van de patiënt tijdens de behandelperiode. b Testosteroncurve van de patiënt tijdens de behandelperiode
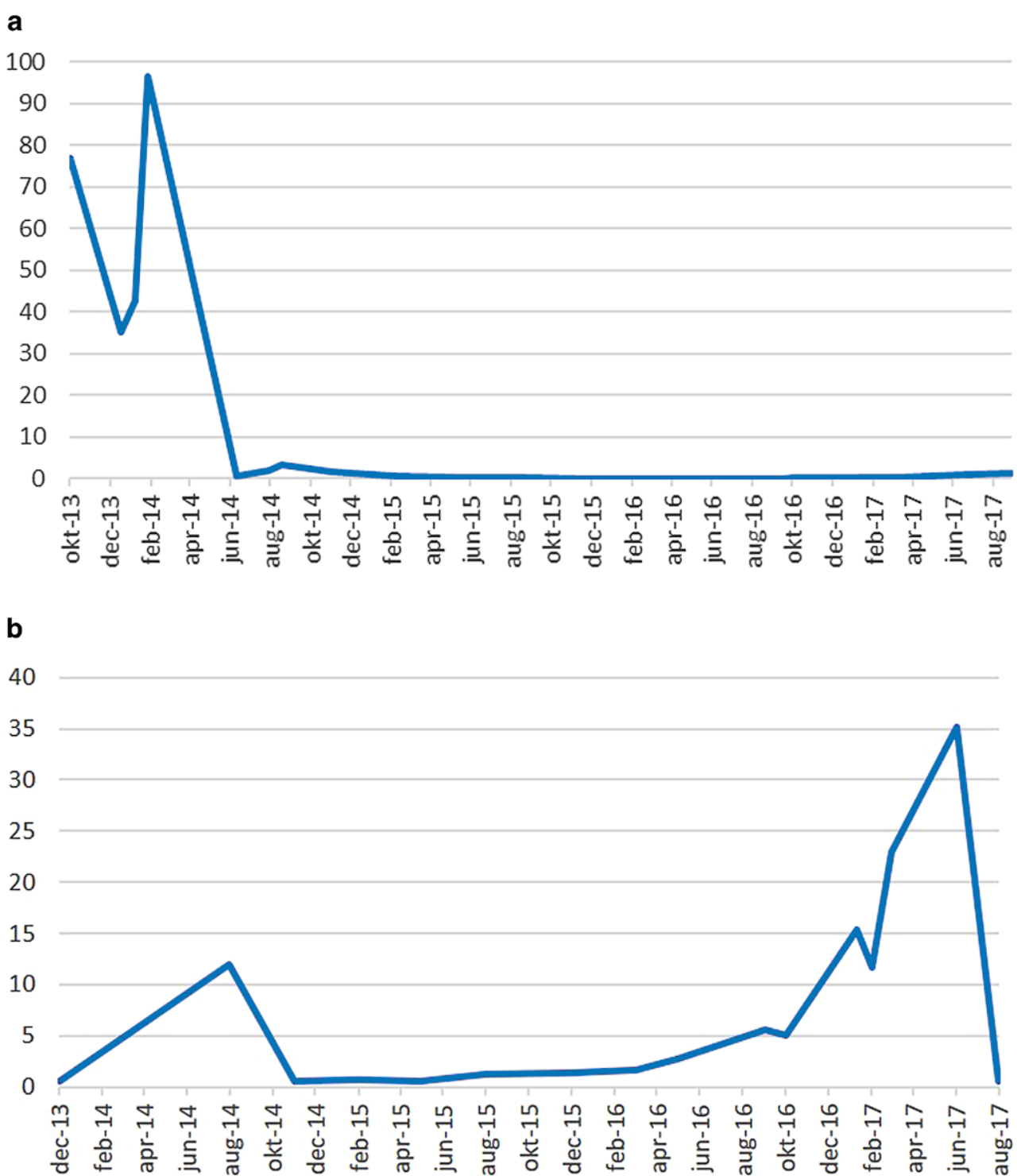

familieanamnese voor prostaatkanker. Er was sprake van een cT3bN0M0 prostaatcarcinoom, Gleason-score $4+5=9$ en iPSA $77 \mathrm{ng} / \mathrm{ml}$. Hij heeft hiervoor in 2014 een nietzenuwsparende robotgeassisteerde laparoscopische radicale prostatectomie met lymfeklierdissectie ondergaan. Voorafgaand aan die operatie is hij drie maanden behandeld met degarelix-injecties. Aanvankelijk werd er met degarelix een goede respons bereikt, maar in de aanloop naar de operatie verdubbelde het PSA van 42,6 naar 96,36. De testosteronspiegel voorafgaand aan de operatie was laag $(<$ $0,5 \mathrm{nmol} / \mathrm{L})$. Het pathologisch stadium was ypT3b N0(0/13) Mx R1, Gleason-score 4+5=9. Het PSA daalde na de ingreep naar $0,52 \mathrm{ng} / \mathrm{ml}$. Vanwege een nieuwe stijging van het PSA werd een choline PET-CT-scan verricht. Hierop werd een snel groeiend lokaal recidief gezien en kliermetastasen rondom de a. iliaca externa beiderzijds.
In verband met zijn relatief jonge leeftijd werd besloten om ook locoregionaal te behandelen. Er werd gestart met salvage externe radiotherapie op de prostaatloge (70 Gy) en bekkenklieren ( $56 \mathrm{~Gy}$, in 35 fracties) en er werd gestart met gosereline-injecties, die werden gepland voor een periode van drie jaar. Het PSA daalde naar onmeetbaar laag. Ondanks gosereline-injecties daalde de testosteronspiegel onvoldoende $(1,3 \mathrm{nmol} / \mathrm{L})$ en werd er gestart met bicalutamide. Vanwege het verder oplopende testosterongehalte werd gosereline vervangen door leuproreline. Desondanks bleef het testosteron doorstijgen en werd leuproreline vervangen door degarelix, gezien daar eerder een succesvolle daling van het testosterongehalte mee was bereikt. De testosteronspiegel steeg echter verder van 5,0 naar $22,9 \mathrm{nmol} / \mathrm{L}$ in vijf maanden tijd. Het PSA-gehalte steeg met de testosteronwaarde mee. Daarop werd er een echo van de linkertestis verricht. Hier werden geen aanwijzingen voor ma- 
Figuur 4 Stroomdiagram van het effect van centrale regulatie van de LH-secretie, de invloed van testosteronafgifte op de prostaatkankercel en mechanismen van androgeenactie in de tumorcel. Ook worden de aangrijpingspunten van hormonale therapie geillustreerd

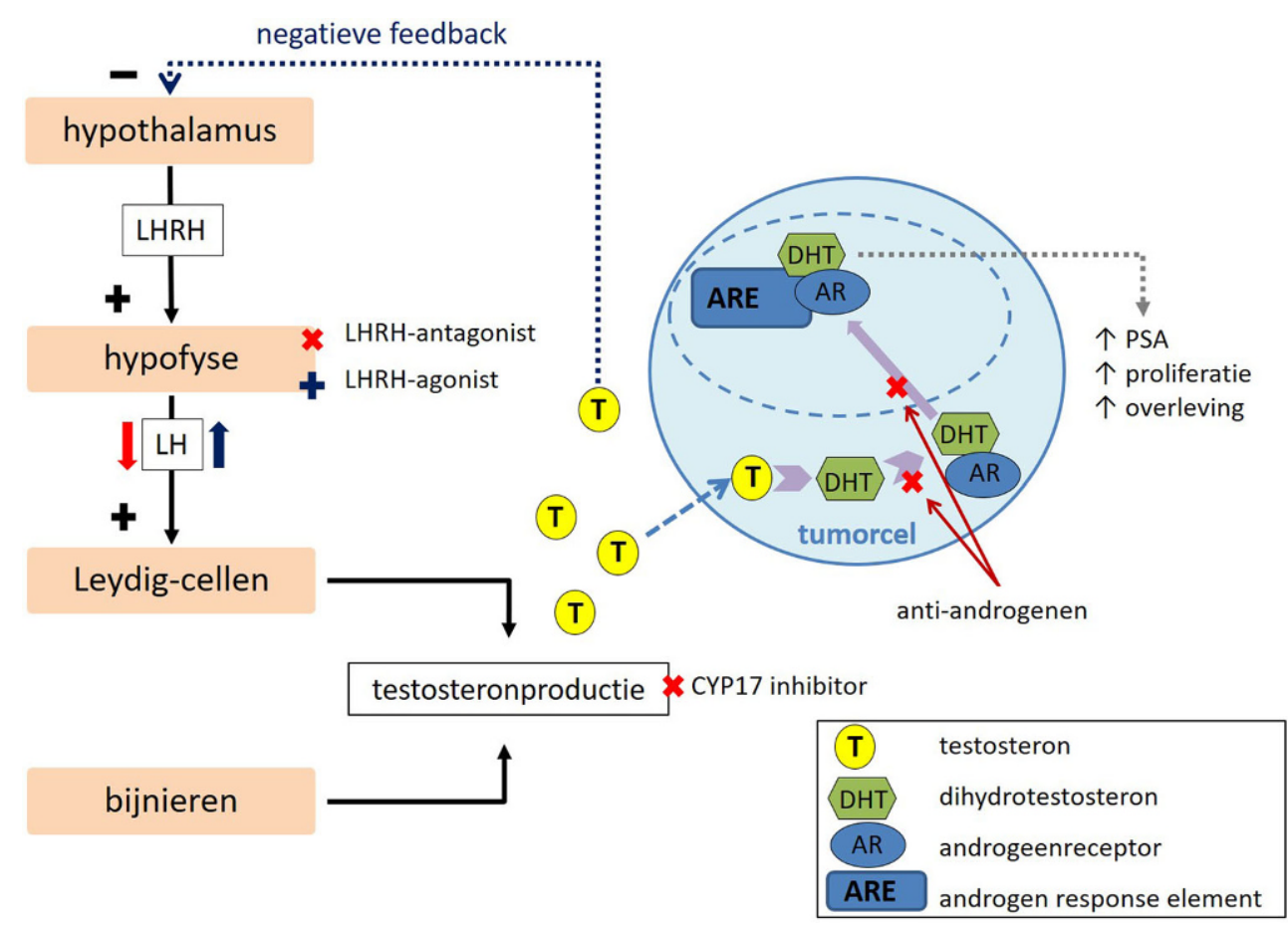

ligniteit gevonden. Op CT-abdomen werd paracavaal een klier gevonden van 4 bij $4 \mathrm{~cm}$ zonder tekenen van maligne laesies elders (fig. 1). Onder verdenking van een metastase van de LCT werd een open retroperitoneale lymfeklierdissectie (paracavaal) verricht. Differentiaaldiagnostisch werd er ook gedacht aan een metastase van het prostaatcarcinoom of een feochromocytoom. Echter, gezien de aanhoudend hoge testosteronspiegel en de afwezigheid van hoge cortisol- of metanefrinewaarden in de 24-uursurine, werd een LCT-metastase waarschijnlijker geacht. De tumoreuze lymfeklier bracht bij pathologisch onderzoek dezelfde markers tot expressie als de primaire LCT en liet geen expressie zien van PSA. De diagnose LCT-metastase kon hiermee worden bevestigd. Postoperatief daalde de testosteronspiegel van 35,1 naar onmeetbaar laag. Na drie jaar werd hormonale therapie gestaakt en blijft het PSA laag (fig. 2, 3a en 3b).

\section{Beschouwing}

De hoeksteen van de hormonale behandeling bij prostaatkanker is het remmen van de functie van testosteron op de prostaatkankercel en daarbij het remmen van de tumorproliferatie. Proliferatie van prostaatkanker wordt geremd door het blokkeren van de androgeenreceptor op de prostaatcel of door het verminderen van de testosteronproductie (fig. 4). Dit laatste kan met behulp van LHRH-agonisten, LHRH-antagonisten of CYP17-remmers (blokkering van de synthese van androgenen).
Er is veelvuldig onderzoek gedaan naar de rol van hormonen bij het ontstaan van prostaatkanker en met name naar de invloed van een verhoogde testosteronspiegel. Onderzoeken laten echter zien dat verhoogde serumconcentraties van testosteron, dihydrotestosteron en overige androgeenderivaten niet geassocieerd zijn met een verhoogd risico op het krijgen van prostaatkanker [4]. Er bestaat daarom geen causale relatie tussen de primaire LCT en het optreden van prostaatcarcinoom [5-8].

Men zou zich kunnen afvragen of de testosteronproductie vanuit de primaire LCT de progressie van prostaatkanker heeft bevorderd. In de jaren zestig van de vorige eeuw heeft Charles Huggins de Nobelprijs gekregen voor het aantonen van een verband tussen de suppressie van testosteronspiegels en de regressie van prostaatkanker [9]. Heden ten dage is het de dagelijkse praktijk om gemetastaseerd of lokaal uitgebreid prostaatkanker te behandelen met medicamenten die zijn gericht op het verlagen van de testosteronspiegels [9]. Hoewel hormonale therapie bewezen effectief is, blijft de rol van testosteron op de uitkomsten bij prostaatkanker erg omstreden. De meeste studies kunnen geen relatie aantonen tussen testosteron en de progressie van prostaatkanker [10]. De patiënt in deze casus had bij de initiële diagnose een hooggradig prostaatcarcinoom met een iPSA van $77 \mathrm{ng} / \mathrm{ml}$. De testosteronwaarde was toen binnen de normaalwaarde $(10 \mathrm{nmol} / \mathrm{L})$, waardoor progressie van prostaatkanker op basis van de primaire LCT onwaarschijnlijk is.

Aanvankelijk had de patiënt na robotgeassisteerde laparoscopische radicale prostatectomie bij laboratoriumonder- 
zoek een snel stijgende PSA-spiegel, wat goed te verklaren was vanuit de iliacale kliermetastasen van het prostaatcarcinoom. $\mathrm{Na}$ adequate behandeling daarvan daalde zijn PSAspiegel naar onmeetbaar laag. Hierna begon het testosterongehalte langzaam te stijgen en daarbij nam ook de PSAwaarde licht toe. Dit kan alleen verklaard worden vanuit een testosteronproducerende bron, omdat de gonadotrofinen maximaal onderdrukt waren en een adrenale oorzaak voor de testosteronproductie was uitgesloten. De LCT-metastase bewerkstelligde oplopende PSA-waarden en heeft daarbij mogelijk een tegengesteld effect gehad op de hormonale behandeling voor prostaatcarcinoom. Anderzijds heeft de hormonale therapie ook mogelijk langdurig de progressie van de LCT onderdrukt.

In de literatuur bestaat slechts één andere casus over een LCT-metastase die endocrien actief was. Deze patiënt had zeven jaar na primaire verwijdering van de LCT een abdominale massa, die zowel testosteron, oestradiol als cortisol produceerde [11]. LCT's metastaseren in de regel niet en dit is naar ons weten de tweede casus over een testosteronproducerende metastase en de eerste waarin deze metastase ontdekt wordt tijdens hormonale behandeling voor prostaatcarcinoom.

\section{Conclusie}

LCT is een zeer zeldzame testiculaire aandoening. De overgrote meerderheid van de patiënten presenteert zich met stadium-I-ziekte. Slechts een klein deel van de LCT's is maligne. Deze maligne LCT's kunnen metastaseren tot jaren na de primaire presentatie. Met deze casus is aangetoond dat een LCT-metastase ectopisch testosteron kan produceren, en dat dit zou kunnen interfereren met de hormonale behandeling van prostaatcarcinoom.

Open Access This article is distributed under the terms of the Creative Commons Attribution 4.0 International License (http:// creativecommons.org/licenses/by/4.0/), which permits unrestricted use, distribution, and reproduction in any medium, provided you give appropriate credit to the original author(s) and the source, provide a link to the Creative Commons license, and indicate if changes were made.

\section{Literatuur}

1. Al-Agha OM, Axiotis CA. An in-depth look at leydig cell tumor of the testis. Arch Pathol Lab Med. 2007;131(2):311-7.

2. Gigantino V, La Mantia E, Franco R, et al. Testicular and testicular adnexa tumors in the elderly. Anticancer Drugs. 2013;24(3):228-36.

3. Bertram KA, Bratloff B, Hodges GF, Davidson H. Treatment of malignant Leydig cell tumor. Cancer. 1991;68(10):2324-9.

4. Endogenous Hormones and Prostate Cancer Collaborative Group, Roddam AW, Allen NE, Appleby P, Key TJ. Endogenous sex hormones and prostate cancer: a collaborative analysis of 18 prospective studies. J Natl Cancer Inst. 2008;100(3):170-83.

5. Rhoden EL, Morgentaler A. Risks of testosterone-replacement therapy and recommendations for monitoring. $\mathrm{N}$ Engl J Med. 2004;350(5):482-92.

6. Krieg M, Nass R, Tunn S. Effect of aging on endogenous level of 5 alpha-dihydrotestosterone, testosterone, estradiol, and estrone in epithelium and stroma of normal and hyperplastic human prostate. J Clin Endocrinol Metab. 1993;77(2):375-81.

7. Heikkila R, Aho K, Heliovaara M, et al. Serum testosterone and sex hormone-binding globulin concentrations and the risk of prostate carcinoma: a longitudinal study. Cancer. 1999;86(2):312-5.

8. Hsing AW. Hormones and prostate cancer: what's next? Epidemiol Rev. 2001;23(1):42-58.

9. Huggins C, Stevens RE Jr., Hodges CV. Studies on prostatic cancer: II. the effects of castration on advanced carcinoma of the prostate gland. Arch Surg. 1941;43(2):209-23.

10. Eisenberg ML. Testosterone replacement therapy and prostate cancer incidence. World J Mens Health. 2015;33(3):125.

11. Schwarzman MI, Russo P, Bosl GJ, Whitmore WF. Hormonesecreting metastatic interstitial cell tumor of the testis. J Urol. 1989;141(3):620-2.

Laura Stokkel medisch student

dr. Henk G. van der Poel uroloog

dr. Sigrun I. Langbein uroloog

dr. J. Martijn Kerst internist-oncoloog

dr. Bas W.G. van Rhijn uroloog 
Hier staat een advertentie.

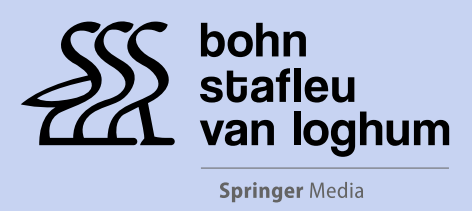

Houten 2018 
Hier staat een advertentie.

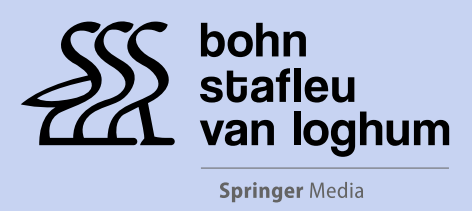

Houten 2018 